\title{
To what extent does UK law protect victims from taking, making and sharing intimate images without consent in an age of emerging technology?
}

Ellie Howarth, Zeynepyade Kola, Haleem Ishfaq, Jade Hughes, Ebony Ibeh

\section{Taksing}

\section{What is "up-skirting"?}

This is an offence which involves someone taking an indecent picture up someone's clothing without their knowledge or consent with intention of viewing their genitals or buttock.

\section{What is "down-blousing"?}

This entails using a mobile phone to take photos down someone's blouse or shirt.

What is "cyber-flashing"?

This offence includes air dropping unsolicited images of someone over the phone.

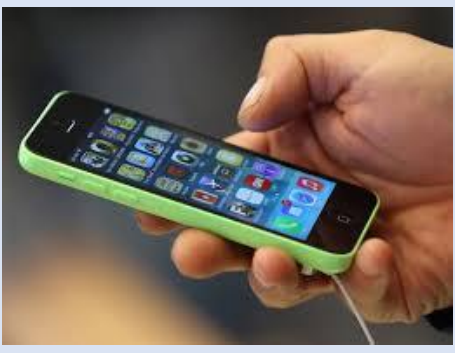

Image taken from independent.co.uk

\section{Malking}

\section{What are deep fakes?}

"Deepfake" refers to a video or image that has been edited and altered using an algorithm/software to distort the person in the original video and replace them with someone else in a way that makes the video look authentic.

What Software can be used?
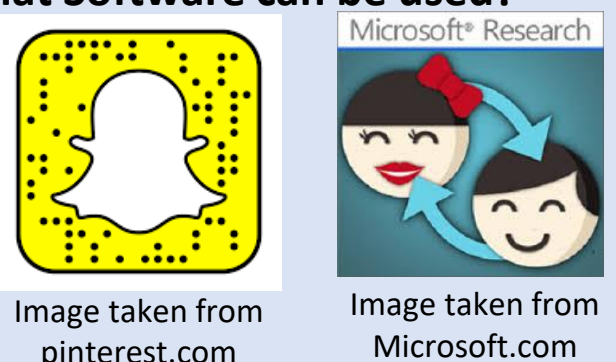

What do these people have in common?

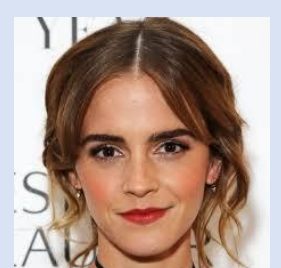

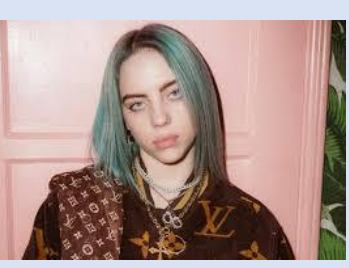

mage taken from thetimes.co.uk

\section{Sha)รับำ}

What is happening behind closed doors during lockdown?

There have been more cases of nonconsensual pornography reported to a dedicated UK helpline so far this year than in all of 2019.

Is a 'safe internet' possible for children? More than 500 children were victims of socalled 'revenge porn' in England and Wales last year.

Is this you?

Today's technology makes it hard for victims to convince other people that it is not them in the video.

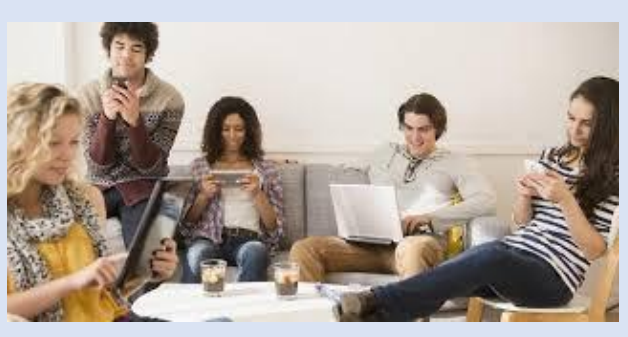

Image taken from digileaders.com 